\section{The American Journal of Psychiatry}

\section{May 2018, Volume 175}

\section{Editorials}

391 Eradicating Traumatic Memories: Implications for PTSD Treatment Matthew J. Friedman

393 Toward Dissemination of Secondary Prevention for Psychosis Robert Rosenheck

395 Mindful Pharmacogenetics: Drug Dosing for Mental Health Julia C. Sting|

398 A Role for Placental CRH in Cortical Thinning and Neuropsychiatric Outcomes

Megan R. Gunnar

\section{Clinical Case Conference}

400 Developmental Delay, Treatment-Resistant Psychosis, and Early-Onset Dementia in a Man With 22q11 Deletion Syndrome and Huntington's Disease

Martilias Farrell et al

\section{Perspectives in Global Mental Health}

408 Failure to Identify a Human Trafficking Victim Mollie Gordon et al

\section{Images in Psychiatry}

410 Addressing the Homeless Mentally III in San Francisco Ira D. Glick

\section{Reviews and Overviews}

411 Early Intervention in Bipolar Disorde Eduard Vieta et al

\section{Articles}

427 Reduction of PTSD Symptoms With Pre-Reactivation Propranolo Therapy: A Randomized Controlled Trial Alain Brunet et al

434 Care Pathways Before First Diagnosis of a Psychotic Disorder in Adolescents and Young Adults Gregory E. Simon et al

443 Effectiveness of Early Psychosis Intervention: Comparison of Service Users and Nonusers in Population-Based Health Administrative Data Kelly K. Anderson et al

453 Cortical Abnormalities Associated With Pediatric and Adult ObsessiveCompulsive Disorder: Findings From the ENIGMA ObsessiveCompulsive Disorder Working Group Premika S.W. Boedhoe et al mpact of CYP2C19 Genotype on Escitalopram Exposure and Therapeutic Failure: A Retrospective Study Based on 2,087 Patients Marin M. Jukic et al

471 Cortical Thinning and Neuropsychiatric Outcomes in Children Exposed to Prenatal Adversity: A Role for Placental CRH? Curt A. Sandman et al

\title{
BJPsych Advances
}

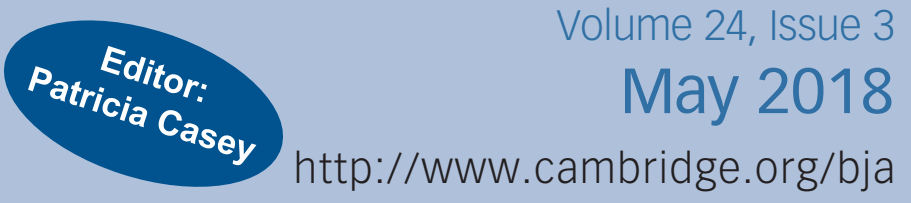

\section{Contents}

Violence and aggression in psychiatric settings: reporting to the police

Susham Gupta, Elvan U. Akyuz, Jonathan Flint \& Toby Baldwin

Stalking risks to celebrities and public figures

Simon Wilson, Charles Dempsey, Frank Farnham, Tony Manze \& Alice Taylor

Substance use disorders and sexually transmitted infections: a public health perspective

Vijaya Murali \& Sabitha Jayaraman

Liaison psychiatry: heart and lung transplantation John D. Sheehan

Evidence-based psychological approaches for auditory hallucinations

Mark Hayward
The neuropsychiatry of multiple sclerosis Maria A. Ron

Interface between general adult and old age psychiatry Oleksandr Khrypunov, Raheel Aziz, Ban Al-Kaissy, Ketan Jethwa \& verghese Joseph

Fusion legislation and forensic psychiatry: the criminal justice provisions of the Mental Capacity Act (Northern Ireland) 2016

Philip Campbell \& Keith Rix

Clozapine use in old age psychiatry

Amey Kirrane, Biswadeep Majumdar \& Anna Richman

Do patterns of synaptic pruning underlie pychoses, autism and ADHD?

Prasanna N. de Silva 